\title{
Application of DC-DC Boost Converter for Solar Powered Traffic Light with Battery Backup
}

\author{
T. S. Anandhi ${ }^{1}$ and S. PremKumar ${ }^{2 *}$ \\ 1Department of Electrical and Electronics Engineering, \\ Jerusalem College of Engineering, Chennai-600100, Tamil Nadu, India; tsanandhi@rediffmail.com \\ 2Department of Electrical and Electronics Engineering, \\ Bharath University, Chennai-600073,Tamil Nadu, India; premkumar.eee@bharathuniv.ac.in
}

\begin{abstract}
The paper presents the application of a DC-DC Boost Convereter for solar powered traffic light equipment for traffic control. The proposed system gives a high performance of the solar powered traffic light equipment whose adaptability are very attractive for the solar array power tracking in dynamic environments. The input is a solar panel that supplies a voltage of $12 \mathrm{~V}$ which is used for this application. The DC Boost converter is successfully implemented using a low cost microcontroller.
\end{abstract}

Keywords: Boost Converter, Solar Panel, Solar Powered Traffic Light Equipment

\section{Introduction}

In India where solar power is available in abundance, it can be made use as an energy source. With the non renewable sources becoming increasingly deficient solar power provides a likely replacement for the non-renewable resources. The climatic condition of India where, about 300 days of clear sunny sky provides a large scope for the use of solar power.The solar power can be developed for long term use and can provide a potential of 20MW per sq. Km.

A solar panel is packaged, connected assembly of solar cells, also known as photovoltaic cells. The solar panel can be used as a component of a larger photovoltaic system to generate and supply electricity in commercial and residential applications. Power produced by a single solar panel is limited. Solar panel uses light energy from the sun to generate electricity through the photovoltaic effect. The structural member of a module can either be the top layer or the back layer. The majority of modules use wafer based crystalline silicon cells or thin-film cells based on cadmium telluride or silicon. Electrical connections are made in series to achieve a desired voltage and in parallel to provide a desired current capability. Currently the best achieved sunlight conversion rate is around $21 \%$ in commercial products typically lower than efficiencies of their cells isolation.

The energy density of a solar panel is the efficiency described in terms of peak power output per unit of surface area, commonly expressed in units of watts per square foot $\left(\mathrm{w} / \mathrm{ft}^{2}\right)$. The most efficient mass produced solar panels have energy density values of greater than 13 $\mathrm{w} / \mathrm{ft}^{2}\left(140 \mathrm{w} / \mathrm{m}^{2}\right)$.

\section{Proposed Model}

The proposed model shows the application of a boost converter with the help of a solar panel to supply to a led load. This can be applied to the traffic light control equipment. The light dependant resistor controls the usage of the battery and the solar panel ${ }^{1}$. During the day time the solar panel charges the battery and also feeds the

*Author for correspondence 
led load. During the night time the battery supplies the load directly and the solar panel and boost converter are isolated from the battery². This basic working explained above is shown in the Figure 1.

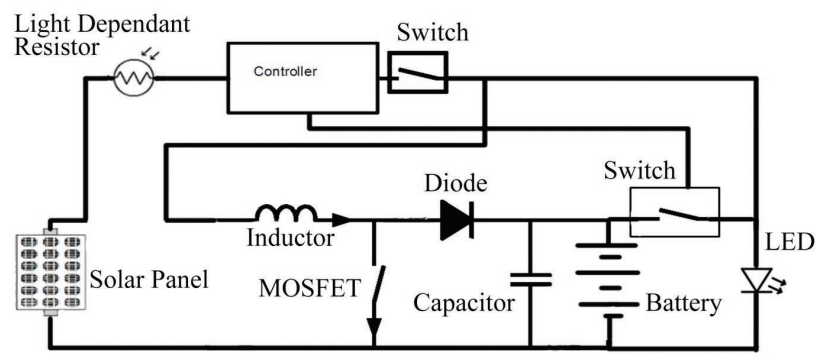

Figure 1. Proposed Model.

\section{Block Diagram}

This is the basic block diagram of the traffic light control equipment. The solar panel is used to charge the battery. The solar panel also supplies the load during the day time when the light source is high. During the night time the solar panel and the boost converter are isolated from the solar panel and the battery solelysupplies the $\operatorname{load}^{3}$. This is shown in the Figure 2.

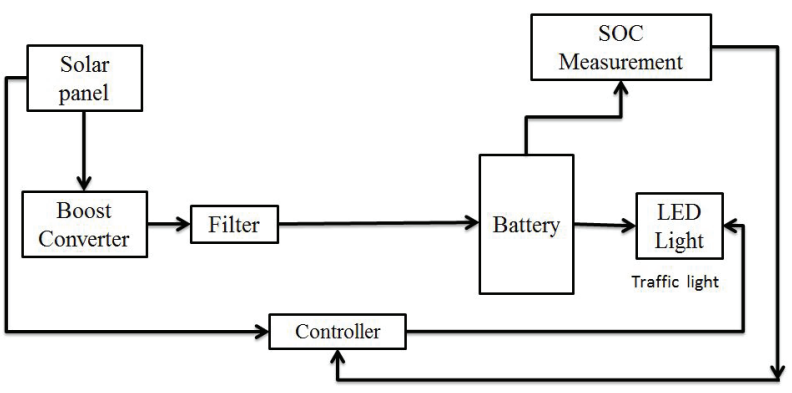

Figure 2.

\section{Photovoltaic Cells}

The solar panel that we have planned to use in our proposed circuit is a $12 \mathrm{~V}, 10 \mathrm{~W}$ panel. The solar panel has a maximum power of $10 \mathrm{~W}$. The voltage at maximum power is $16.8 \mathrm{~V}$. It has a open circuit voltage of $21 \mathrm{~V}^{4}$. The current at maximum power is $0.58 \mathrm{~A}$. The short circuit current is $0.63 \mathrm{~A}$. The Figure 3 represents the block diagram of a solar cell that has a series resistance $\mathrm{R}_{s}$ in parallel with the combination of a current source, 2 diodes, and a resistor $\mathrm{R}_{\mathrm{p}}$. The output current is given by Equation (1).

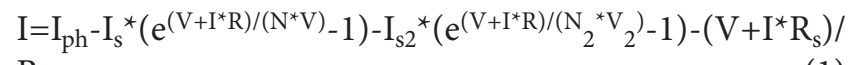

$\mathrm{R}_{\mathrm{p}}$

where $\mathrm{I}_{\mathrm{ph}}$ is the solar induced current.

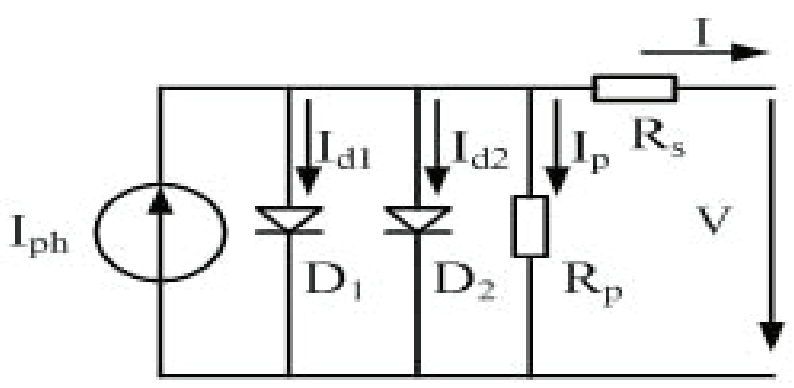

Figure 3.

\section{Boost Converter Circuit}

The boost converter circuit which is used to boost the voltage that is obtained from the solar panel. This boosted voltage is used for charging the battery, since the battery requires higher potential than its own potential to be charged ${ }^{5}$. This requires the help of the boost converter, since the voltage output from the solar panel is $12 \mathrm{~V}$ or less. The boost converter is shown in the Figure 4 .

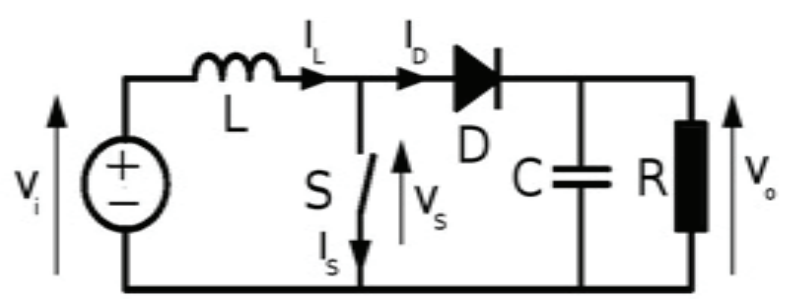

Figure 4. Boost Circuit.

\section{Design Calculation and Simulation}

The boost converter circuit is operated under the Frequency of $31250 \mathrm{~Hz}$. The values of the inductance and the capacitance can be calculated with the equation (2) and (3) given below 6 .

Minimum Inductor Value $=\mathrm{d}^{\star} \mathrm{v}_{\text {in }}{ }^{*}(1-\mathrm{d}) /$ freq $\left.^{*} 2^{\star} \mathrm{v}_{\text {out }}\right)=$ $73.46 \mathrm{mH}$

Minimum capacitor value $=\mathrm{I}_{\text {out }} /\left(\mathrm{v}_{\text {ripple }}{ }^{\star}\right.$ freq $)=102.4 \mu \mathrm{f}$

The duty cycle under which the boost converter is operated is given by the Equation (4) that is: 


$$
\text { Duty Cycle }=1-\left(\mathrm{v}_{\text {in }} / \mathrm{v}_{\text {out }}\right)=14.2 \%
$$

With the above implementation of the open loop boost converter, the voltage that is received from the panel is boosted and then used for the charging the battery ${ }^{7}$. The implemented boost converter is used is shown in the Figure 5(a). The output of the boost converter which settles down after an initial transient period. This is shown in the Figure 5(b) ${ }^{8}$.
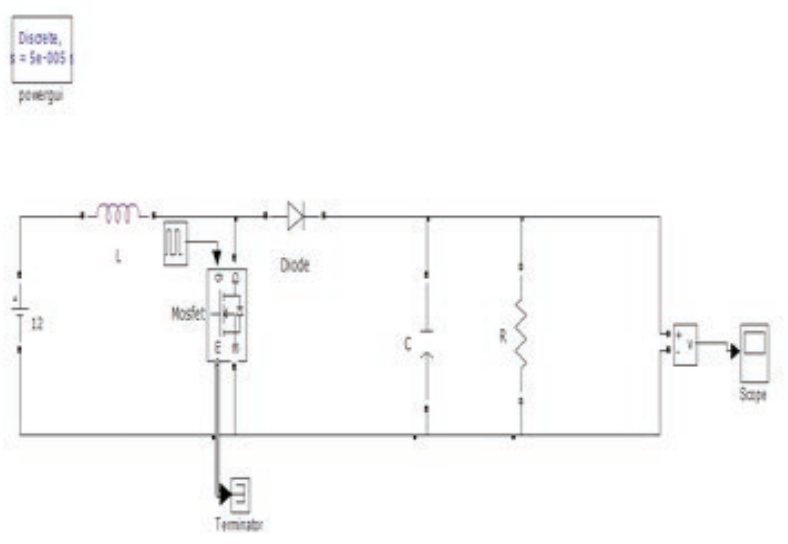

Figure 5(a). Open Loop Boost Converter Circuit.

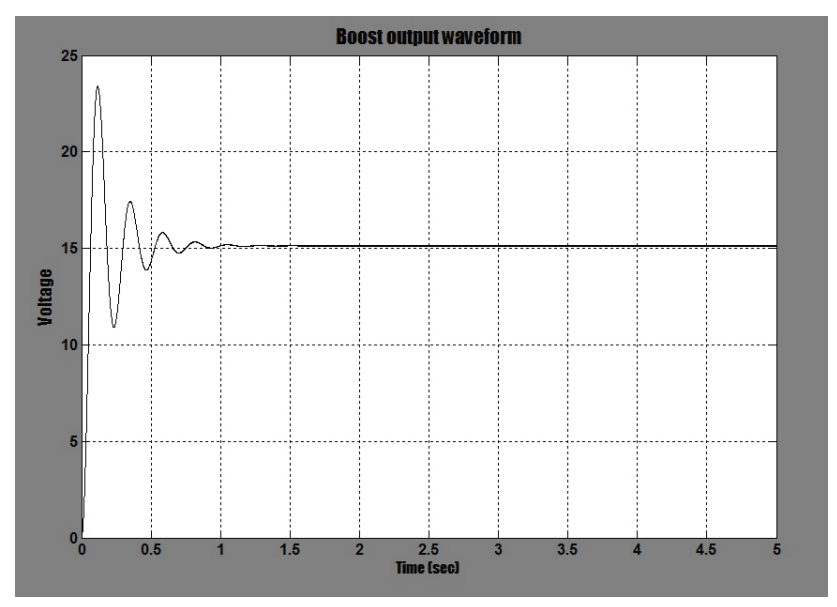

Figure 5(b). Output of Boost Converter.

A slight disturbance is given at the input of boost converter to check the consistency of the circuit and the circuit is unstable and inconsistent. It does not settle at the required value of voltage ${ }^{9}$. This is shown in the Figure 5(c). The output of the circuit is very unstable and also is not consistent. The output of the open loop is as shown in the Figure 5(d).

The closed loop is implemented for the boost converter for the purpose of system stability under a slight disturbance condition. The pulse given to the gate of the

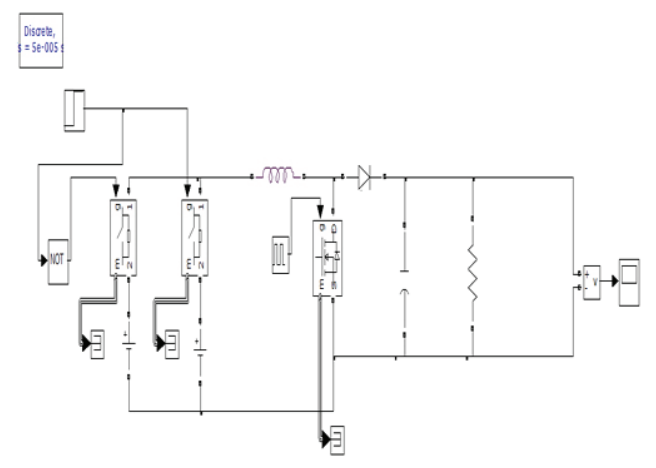

Figure 5(c). Open Loop Boost Converter Circuit with Disturbance.

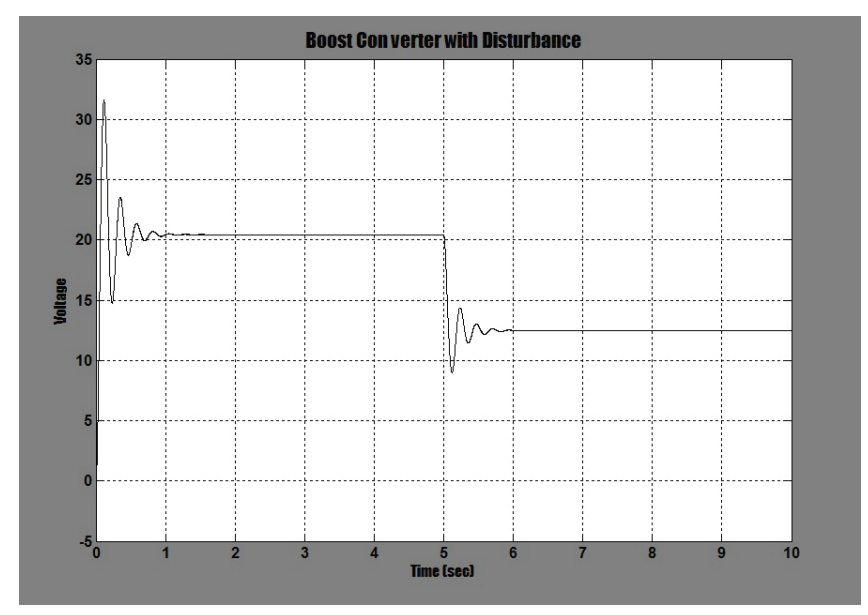

Figure 5(d). Output of Boost Converter with Disturbance.

MOSFET is generated with the help of a PI controller ${ }^{10}$. A slight disturbance is given at the input of boost converter to check the consistency of the circuit and the circuit is stable and consistent. This is shown in the Figure 5(e). This output the waveform settles at the required value. The output of the closed loop is as shown in the Figure $5(\mathrm{f})^{14}$.

The proposed circuit shows the operation of the open loop boost converter coupled with a battery. The boost converter boosts the voltage received from the solar panel. This boosted output voltage charges the battery. The battery supplies to the load when it is fully charged. The battery charge is continuously monitored with the help of the State Of Charge. When the set limit is arrived the solar panel charges the battery and the supply to the load is cut off. This is shown on the Figure $5(\mathrm{~g})$. The output of the proposed circuit shows the State Of Charge of the battery and also the power output of the LED. The Figure 5(h) shows the output of the proposed circuit in open loop. 


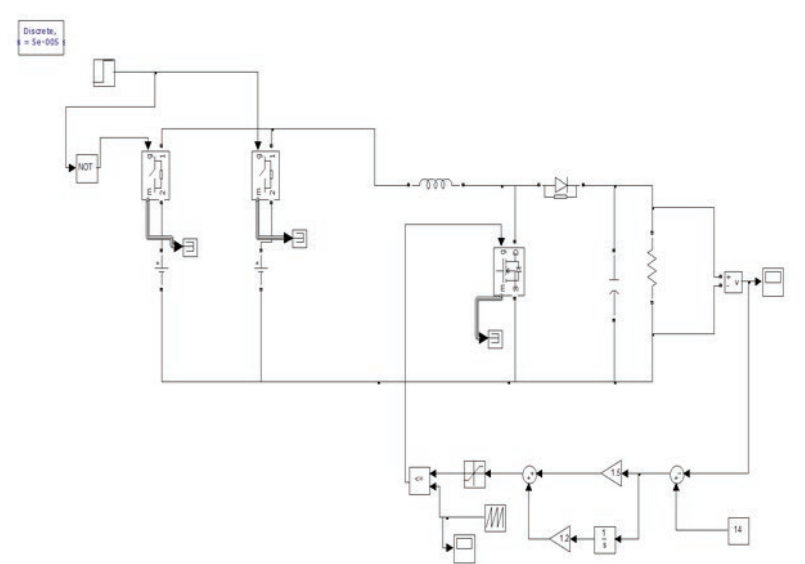

Figure 5(e). Closed Loop Boost Converter Circuit with Disturbance.

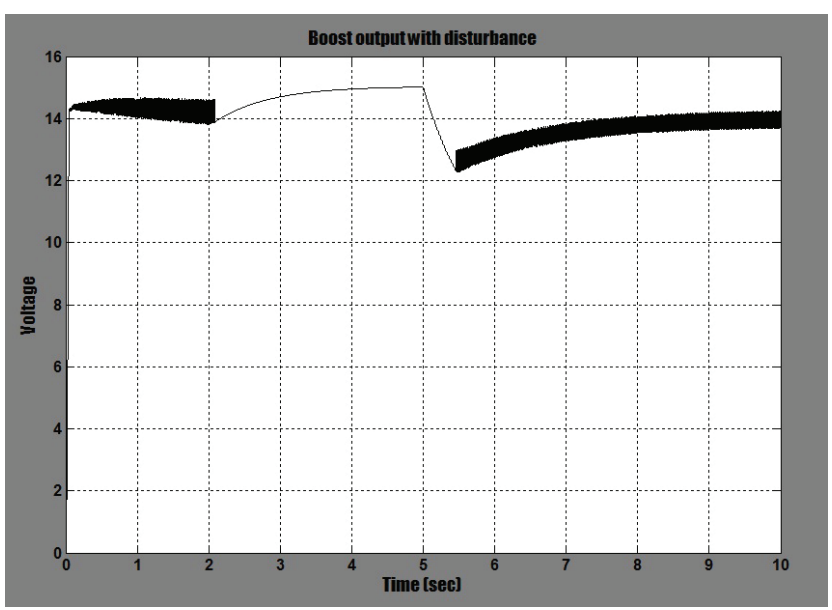

Figure 5(f). Closed Loop Output of Boost Converter with Disturbance.

In the closed loop of the circuit the boost converter is implemented. The solar panel is used to supply to charge the battery. The charged battery is used to supply to the load when the panel is cut off. This is shown in the Figure 5(i).

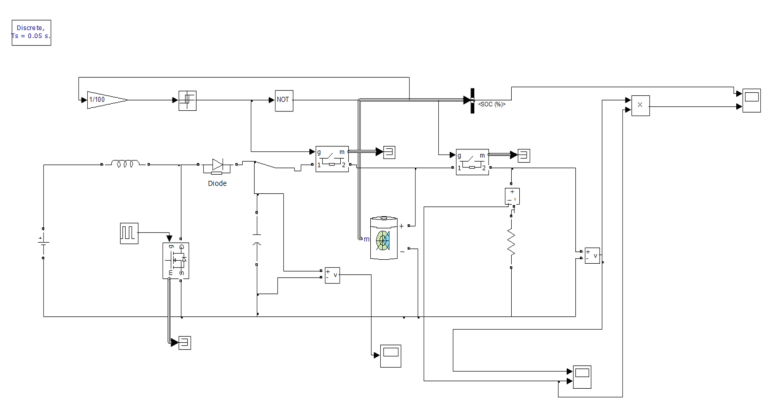

Figure 5(g). Open Loop Circuit.

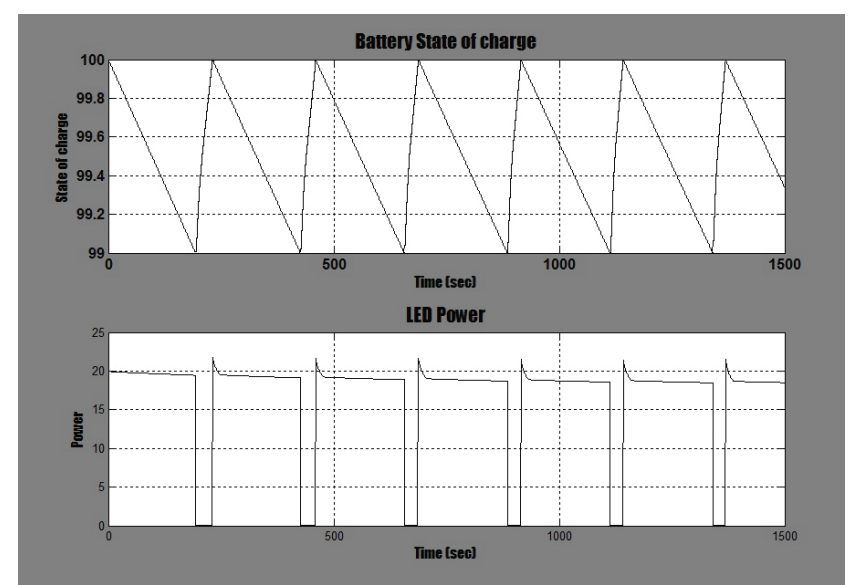

Figure 5(h). SOC and Power Waveforms of Proposed Circuit in Open Loop.

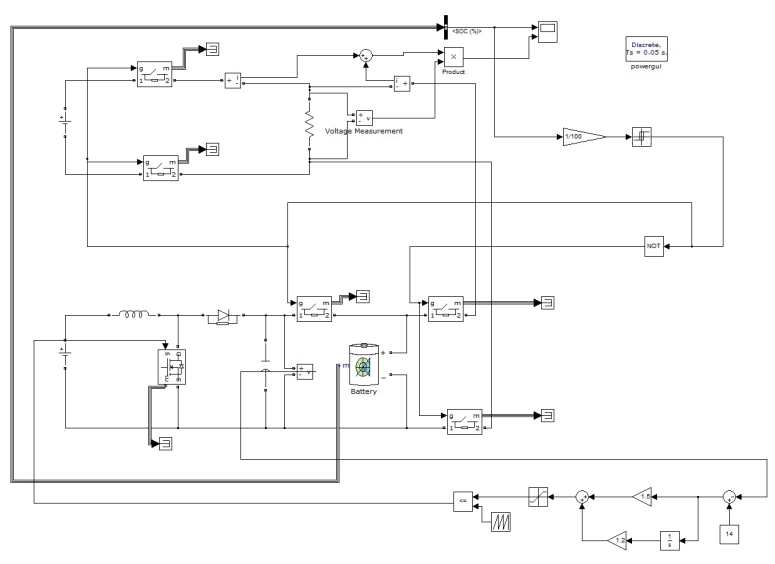

Figure 5(i). Closed Loop Circuit.

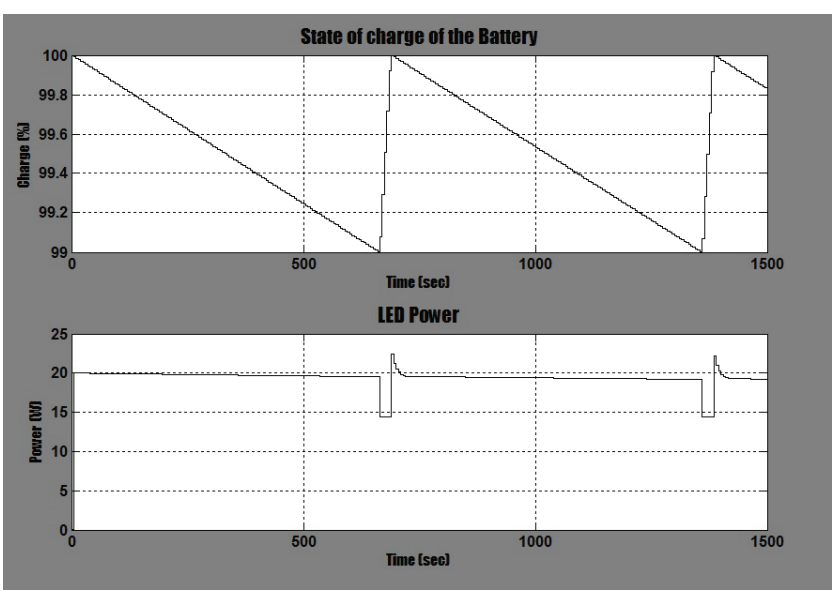

Figure 5(j). SOC and Power Waveforms of Proposed Circuit in Closed Loop.

During the time when the battery is operated the boost converter is isolated from the battery. Thus the solar panel is still connected to the boost converter. So at this instant 
an open circuit occurs which may result in very high voltage.

To prevent this, a failsafe resistance is implemented in the circuit. This failsafe resistance comes into play only when the battery supplies to the load. Other times this resistance is isolated from the whole circuit.

The waveform shows the State Of Charge of the battery and the output power of the LED load. The period where there is a stand still is the time period where both switches are open. The Figure 5(j) shows the output of the circuit in closed loop.

\section{Conclusion}

The paper presents a model of the solar powered traffic light equipment in places of high solar power availability. The solar array used is of much lesser rating and is highly efficient. The model can be implemented in normal on an AT89C51 microcontroller. With the help of this model the efficiency is improved. This circuit presents the basic model of the Solar Powered Traffic Light Equipment.

The proposed model can be implemented with the help of two solar panels, one supplying to the load directly and another to charge the battery. This can be implemented with the help of a Light Dependant Resistor, which is controlled by the microcontroller. The simulation is done using MATLAB software. In the near future the proposed model can be implemented as the work is under progress.

\section{References}

1. Vieira JAB, Mota AM. Implementation of a Stand-Alone Photovoltaic Lighting System with MPPT Battery Charging and LED Current Control. IEEE International Conference on Control Applications; Yokohama. 2010. p. 185-90. Japan; 2010 Sep8-10.

2. Lakshmi K, Chitralekha S, Illamani V, Menezes GA. Prevalence of bacterial vaginal infections in pre and postmenopausal women. International Journal of Pharma and Bio Sciences. 2012; 3(4):949-56. ISSN : 0975-6299.

3. de Brito MAG, Sampaio LP, Luigi G Jr, e Melo GA, Canesin CA. Comparative Analysis of MPPT Techniques for PV Applications. Applications. 2011 International Conference on Clean Electrical Power(ICCEP); Ischia. 2011. p. 99-104.

4. Sharmila S, Jeyanthi Rebecca L, Das MP. Production of Biodiesel from Chaetomorpha antennina and Gracilaria corticata. Journal of Chemical and Pharmaceutical Research. 2012; 4(11):4870-4. ISSN: 0975-7384.

5. Noh' H-J, Lee D-Y, Hyun D-S. An Improved MPPT Converter with Current Compensation Method for Small Scaled PV-Applications. Applications. IEEE 28th Annual Conference of the Industrial Electronics Society; IEEE. 2002; 2:1113-8.

6. Rajkumar B, Vijay Kalimuthu B, Rajkumar R, Santhakumar AR. Proportioning of recycled aggregate concrete. Indian Concrete Journal. 2005; 79(10):46-50. ISSN:0019-4565.

7. Wu T-F. Chang C-H, Chen Y-K. A Fuzzy-Logic-Controlled Single-Stage Converter for PV-Powered Lighting System Applications. IEEE Trancations on Industrial Electronics. 2000; 47(2):287-96.

8. Vijayaprakash S, Langeswaran K, Jagadeesan AJ, Rveathy R, Balasubramanian MP. Protective efficacy of Terminalia catappa L. leaves against lead induced nephrotoxicity in experimental rats. International Journal of Pharmacy and Pharmaceutical Sciences. 2012; 4(S3):454-8. ISSN: 0975-1491.

9. Khaehintung N, Sirisuk P. Microcontroller Built-in Fuzzy Logic Controller of Maximum Power Point Tracking for Solar-Powered Light-Flasher Applications. Industrial Electronics Society (IECON 2004). 30 ${ }^{\text {th }}$ Annual Conference of 2004; 3:2673-78.

10. Khaehintung N, Pramotung K, Sirisuk P. RISC microcontroller built-in fuzzy logic controller for maximum power point tracking in solar-powered battery charger. Proceedings of IEEE TENCON 2004 Conference. 2004; 4:637-40.

11. Shanthi B, Revathy C, Devi AJM, Parameshwari PJ, Stephen T. Serum 25(OH)D and type 2 diabetes mellitus. Journal of Clinical and Diagnostic Research. 2012; 6(5):774-6. ISSN:0973-709X. 